Relations industrielles

Industrial Relations

\title{
Rétrospective 1947
}

\section{La Direction}

Volume 3, numéro 4, décembre 1947

URI : https://id.erudit.org/iderudit/1023583ar

DOI : https://doi.org/10.7202/1023583ar

Aller au sommaire du numéro

\section{Éditeur(s)}

Département des relations industrielles de l'Université Laval

ISSN

0034-379X (imprimé)

1703-8138 (numérique)

Découvrir la revue

Citer cet article

La Direction (1947). Rétrospective 1947. Relations industrielles / Industrial Relations, 3(4), 49-51. https://doi.org/10.7202/1023583ar

Tous droits réservés ( $@$ Département des relations industrielles de l’Université Laval, 1947
Ce document est protégé par la loi sur le droit d'auteur. L'utilisation des services d'Érudit (y compris la reproduction) est assujettie à sa politique d'utilisation que vous pouvez consulter en ligne.

https://apropos.erudit.org/fr/usagers/politique-dutilisation/ 
publié par le Département des relations industrielles de la Faculté des sciences sociales de Laval, Québec

\section{RÉTROSPECTIVE 1947}

L'année s'achève dans la paix industrielle. L'esprit de Noël et du Jour de l'An invite du reste à la concorde même dans le domaine des relations patronales-ouvrières. C'est une occasion de faire quelques réflexions sur le bilan de l'année.

L'économie d'après guerre n'est pas encore stabilisée. Conınent pourrait-il en être autrement avec une situation politique internationale confuse ? Comment le secteur américain de l'économie mondiale dont nous sommes, pourrait-il trouver son équilibre alors que l'Europe et l'Asie ne sont pas encore sorties d'un chaos politico-économique voulu par le communisme ? Les prix sont à la hausse, le coût de la vie a augmenté et les salariés ont dû batailler pour obtenir un ajustement correspondant de leurs revenus.

Dans le Québec, il faut s'en réjouir, les négociations collectives entre patrons et salariés se sont déroulées presque toujours dans lharmonie. Les organisations ouvrières se sont montrées actives mais raisonnables dans leurs revendications et les employeurs ont accueilli celles-ci dans une large mesure. A noter aussi que nous jouissons presque de la plénitude de l'emploi et que la loi de l'offre et de la demande joue du côié des travailleurs.

Comment dans tout cela s'est comportée notre législation provinciale sur les relations du travail ? 1947 a été une année significative, car depuis l'an dernier nous n’avions plus le contrôle des salaires sous l'arrêté fédéral C.P. 9384. Il faut admettre que nos lois du travail ont subi assez heureusement l'épreuve. Nous soulignerons cependant quelques carences.

Au chapitre de la Loi des relations ouvrières, tout n'a pas marché sans accrochage. Il s'agit d'une loi en somme toute nouvelle. Elle date de 1944. Elle implique une révolution profonde du droit ouvrier. La convention collective est reconnue de bien commun, car on oblige de part et d'autre employeurs et syndicats ouvriers à négocier de bonne foi. Le droit d'association et la liberté syndicale sont protégés par la mise au ban de certaines pratiques interdites. L'organisation ouvrière la plus représentative est légalement reconnue agent négociateur du groupe des salariés dont les intérêts sont en jeu. Mais les hommes sont restés des hommes et la procédure tracassière leur a servi d'outil. La Commission qui applique la loi a été la cible de nombreuses attaques: retards, décisions non toujours motivées, arrêts suspendus ou revisés, etc. La tâche reste difficile. Ne faudrait-il pas un code de procédure qui protège la Commission contre ses errements possibles? Ne serait-il pas à souhaiter que ses décisions passées lui servent de jurisprudence et pour cela qu'elles soient classifiées ?

On reproche à la Commission des faiblesses imputables à la Loi. La Commission est administrative et non judiciaire. Comment peut-elle mettre un frein aux pratiques interdites quand ses décisions ne sont pas exécutoires? Ne faudrait-il pas une Cour du travail qui rendrait jugement sur les pratiques interdites et sur les conflits de droit ? Cette juridiction devrait être spécialisée et la procédure très sommaire.

Patrons et ouvriers ne sont pas sans reproche. Les premiers utilisent les services de procureurs et provoquent souvent de nombreuses et interminables auditions. Les seconds font face au pluralisme syndical qui engendre souvent le recours à des moyens de lutte qui versent dans l'électoralisme.

La certification du syndicat agent-négociateur ne règle pas tout. Les négociations collectives doivent s'entamer entre les parties. Elles sont souvent laborieuses mais nous constatons une grande amélioration dans les techniques des représentants des parties. Les contacts sont déjà établis grâce aux accords antérieurs. Seules quelques clauses de conventions sont litigieuses: salaires, congés payés, sécurité syndicale, classification des emplois et évaluation des 


\section{Bulletin des relations industrielles}

Volume 3, numéro 4

Décembre 1947

publié par
le Département des relations industrielles
de Laval.

T.R.P. Georges-H. LEvesQue, o.p., doyen. Gérard TREMBLAY, directeur.

J. O'CONNELL-MAHER, assistant-directeur.

Abbé Gérard Dion, secrétaire.

Charles Bélanger et. Jean Gagné, assistantssecrétaires.

$\begin{array}{lr}\text { ABONNEMENT: } & \text { Canada } \$ 1.50 \\ \text { Etranger } \$ 2.00 & \text { Le numéro } \$ 0.20\end{array}$

Adressez toute correspondance au Secrétaire

Département des relations industrielles, Faculté des sciences sociales,

Université Laval,

Québec, P.Q.

\section{SOMMAIRE}

Rétrospective 1947

LA Direction..

Réflexions sur les grèves

Omer Genest.

Une solution courageuse

W. J. WhITEHEAD

Our Industrial Relations Plan

W. J. Whitehead.. ... ..

Manuels Techniques français.. ...

Association et corporation.

Nos collaborateurs.

Retrospective I947.

64 normes de travail. Une bonne moitié des conventions se négocient normalemént sous l'intervention du Service de Conciliation. Une enquête sérieuse. nous révèle que le Service provincial de Conciliation à Montréal comme à Québec est tout à fait efficace. Bien rares sont les agents d'employeurs ou d'organisations ouvrières qui ne reconnaissent pas le dévouement, la compétence et les réussites des conciliateurs du Ministère du Travail.

Si habiles que soient des conciliateurs, ils connaissent des échecs. C'est alors, en vertu de la loi, le recours à la procédure d'arbitrage. Les rapports du Ministère nous informent que plus de cent tribunaux d'arbitrage ont siégé au cours de l'année. Une quarantaine sont encore en fonction. Les uns sont dissous, d'autres s'organisent, si bien que durant l'année de trente à quarante tribunaux ont siégé en même iemps. La procédure d'arbitrage est obligatoire dans le Québec et le capital et le travail s'en trouvent assez bien. Comment régler autrement les conflits d'intérêts si on veut prévenir la grève ou le lock-out ?

On reproche aux tribunaux leur lenteur. Quelques-uns ont siégé plusieurs mois; en moyenne, les séances se prolongent durant plus de deux mois. Les ouvriers s'impatientent, car déjà les procédüres de certification, de négociation et de conciliation ont accumulé des délais. On pourra dire que la sentence sera rétroactive, mais il reste que des délais prolongés obligent souvent les ouvriers à des compromis coûteux sur la rétroactivité. Le législateur doit donc viser à réduire au minimum ces délais. La sentence devrait être rendue dans les trois mois à compter de la constitution du tribunal; aujourd'hui l'instruction peut se prolonger indéfiniment bien que la sentence doive être rendue dans les trente jours à compter de la fin de l'instruction. Il faudrait aussi permettre au Ministre de nommer d'office l'arbitre de l'employeur ou des salariés quand ceux-ci ne s'entendent pas dans un délai raisonnable: Tout procédé dilatoire en somme doit être extirpé.

Il n'y a pas de doute que notre Code des relations du travail doive être refait. N'oublions pas que si la Loi des relations ouvrières date de 1944 et a été amendée deux fois depuis, la Loi des différends ouvriers date de 1909 dans sa forme actuelle. Il y a nécessité d'intégration, de mise au point. Souhaitons que le législateur reconnaisse l'importance de bonnes lois du travail s'il veut sauvegarder 'a paix sociale.

Il faut admettre, par ailleurs, que si importantes que soient les lois qui les régissent, les relations du travail sont avant tout humaines. La droiture et la bonne foi seules permettent une sage application des lois. Nous nous rendons compte du reste qu'employeurs et syndiqués de plus en plus s'adaptent au climat de la légalité et de l'ordre. Il ne s'agit pour s'en rendre compte que de suivre la chronique ouvrière. De plus en plus rares sont ceux qui violent grossièrement la législation actuelle. Au surplus, les violateurs de la loi n'ont guère obtenu de dividendes dans le Québec. Il en a coûté à un employeur près de cent mille dollars pour substituer un syndicat autonome à un syndicat reconnu. La grève de l'union des tisserands chez Ayers où la procédure d'arbitrage avait été ignorée a été un insuccès et s'est terminée en Cour d'Assises. La grève des salaisons où l'union n'a pas voulu de conciliation provinciale s'est traduite par la perte de trois ou quatre unions locales pour I'Union internationale des Ouvriers des Sa- 
laisons. La grève du C.C.T. dans la chaussure à Montréal, déclarée en violation des procédures de conciliation et d'arbitrage, est une affaire perdue. Nous ne voulons pas mettre en cause ici les revendications des travailleurs; elles étaient fondées puisque des ajustements ont été accordés. Nous désirons simplement mettre en vedette cette vérité que l'illégalité ne paie pas plus l'union que lemployeur. Des centaines d'unions de la C.T.C.C., du C.M.T. et du C.C.T. ont, par contre, respecté la loi et s'en sont bien trouvées. L'opinion publique supporte encore chez nous, Dieu merci, le régime de la loi et de l'ordre. Qu'on se rappelle les tractations heureuses qui ont suivi les grèves légales à l'Associated Textiles Limited et à la Dominion Textile Company Limited.

Cette rétrospective de l'année syndicale nous amène à conclure que les lois sont sans doute perfectibles mais que la principale réforme reste encore celle des moeurs.

\section{La Direction}

\section{RÉFLEXIONS SUR LES GRÈVES \\ Omer GENEST, ptre}

\section{Une grève, pourvu qu'elle soit LEGALE est-elle MORALEMENT juste? Faut-il condamner en MORALE toute grève ILLEGALE?}

Les grèves, voilà un sujet d'inquiétante actualité. Nous en avons connu, ces dernières années, de fort considérables, de violentes et de paisibles. Récemment, quelques minutes avant l'heure « $G$ », des grèves imminentes furent évitées de justesse, celle des marins, celle des employés de chemin de fer. En France, en Italie, les ouvriers cessent de travailler par centaines de mille, par millions. Les Etats-Unis, après quelque dix-huit mois de paix industrielle vont, selon toute probabilité, subir en 1948 des conflits d'importance par. suite de la décision des unions américaines de réclamer de substantielles augmentations de salaire.

Le fait de la grève produit un effet terrifiant sur les esprits petits-bourgeois qui n'ont jamais pris la peine de comprendre le problème ouvrier. Leur phobie naive du communisme leur fait voir du rouge partout. La peur d'être dérangés dans leur vie calme et douce les porte d'instinct à condamner ceux qui assument les risques d'une lutte pour défendre leurs intérêts menacés. La grève pour eux, c'est la calamité des calamités : l'auteur de l'Apocalypse aurait dû la placer parmi les fléaux qui marqueront la fin du monde.

Qu'il y ait eu des grèves accompagnées de violences, de coups de poing et d'effusions de sang, l'histoire malheureusement l'a enregistré. Mais avant d'en blâmer les ouvriers, il faut rappeler que certains patrons ont eu recours à des tactiques provocatrices, à des mesures de banditisme pour briser l'union de leurs employés qui se défendaient comme ils pouvaient. Plusieurs enquêtes du Sénat américain l'ont prouvé d'une façon irréfutable.

Que des agitateurs aient noyauté le mouvement ouvrier pour le pousser à des cessations de travail injustifiables qui attaquaient sans raison des patrons bien disposés, mais qui n’avaient pas d'autre but que d'être une «initiation réduite, un essai, une préparation du grand bouleversement final » (Georges Sorel). Car dans l'esprit des radicaux, ces grèves en plus d'entretenir le mécontentement populaire, de fomenter des rancours haineuses, entraìnent le prolétariat à s'unir, à se discipliner, afin de pouvoir déclancher un jour la grève générale, premier acte de la révolution qui abattra une structure économique et sociale où «s'accroît la misère, l'oppression, l'esclavage, la dégradation, l'exploitation, » disait Marx, leur maître, dans son «Capital».

Malgré tous ces excès, il faut admettre que, depuis cent ans, les ouvriers ont réussi à améliorer leurs conditions de salaire, de travail et de vie en s'unissant d'abord, puis en maniant l'arme de la grève. Il leur en a beaucoup coûté parfois et la libération de la classe ouvrière dont notre siècle se vante a eu ses martyrs et ses héros. Les grèves, même celles dont l'échec paraissait une capitulation, même les simples menaces de grève * ont cer- 